\title{
Proses pembelajaran gitar klasik sebagai nilai-nilai pendidikan di Prodi Pendidikan Seni Pertunjukan FKIP \\ Untirta
}

\author{
Syamsul Rizal \\ Universitas Sultan Ageng Tirtayasa \\ Correspondence : syamsul.rizal@untirta.ac.id
}

\begin{abstract}
Learning guitar in the Performing Arts Education Study Program (PSP) FKIP Untirta is an effort made by students to play an existing repertoire created by a composer. The repertory is studied gradually and continuously. From the beginning to the end of the repertory, students play with the techniques, dynamics, and tempo written from a repertory. This is a process that is carried out continuously by the students of PSP FKIP Untirta. The guitar learning process is certainly interesting to be used as a study. Given that there is no guitar learning in PSP FKIP Untirta that has made a scientific study material. This study used a qualitative method described descriptively to obtain data about educational values in classical guitar learning at PSP FKIP Untirta. This study will discuss the educational values that exist in classical guitar learning in PSP FKIP Untirta. The results of this study are as follows. Educational values in classical guitar learning at PSP FKIP Untirta (1) Discipline values; (2) the value of hard work; (3) the value of being used to reading; and (4) aesthetic value / taste.
\end{abstract}

Keywords: learning, classical guitar, educational value

\begin{abstract}
Abstrak
Pembelajaran gitar yang ada di Prodi Pendidikan Seni Pertunjukan (PSP) FKIP Untirta adalah sebuah upaya yang dilakukan oleh mahasiswa/mahasiswi untuk memainkan repertoar yang sudah ada diciptakan oleh komposer. Repertoar tersebut dipelajari secara bertahap dan berkesinambungan. Mulai dari awal sampai akhir repertoar, para mahasiswa memainkan dengan teknik, dinamik, dan tempo yang tertulis dari sebuah repertoar. Hal ini menjadi sebuah proses yang dilakukan secara terus menurus oleh para mahasiswa PSP FKIP Untirta. Proses pembelajaran gitar tersebut tentunya menarik untuk dijadikan sebuah kajian. Mengingat pembelajaran gitar yang ada di PSP FKIP Untirta belum
\end{abstract}


ada yang menjadikan suatu bahan kajian ilmiah. Penelitian ini menggunakan metode kualitatif yang diuraikan secara deskriptif untuk memperoleh data tentang nlai-nilai pendidikana dalam pembelajaran gitar klasik di PSP FKIP Untirta. Kajian ini akan membahas nilai-nilai pendidikan yang ada dalam pembelajaran gitar klasik di PSP FKIP Untirta. Hasil penelitian ini adalah sebagai berikut. Nilai-nilai pendidikan dalam pembelajaran gitar klasik di PSP FKIP Untirta (1) nilai Disiplin; (2) nilai kerja keras; (3) nilai terbiasa membaca; dan (4) nilai estetis/olah rasa.

Kata kunci : pembelajaran, gitar klasik, nilai Pendidikan

\section{Pendahuluan}

Seni adalah media untuk mengeksperikan sesautu. Melalui seni manusia bisa mengekspresiakannya dalam bentuk salah satunya melalui tulisan, audio, visual, atau audio visual. Sehingga melalui ekspresi tersebut, seseorang bisa menyampaikannya kepada orang lain. Dengan demikian ekspresi yang disampaikan oleh seseorang memiliki nilai seni yang bisa diinterpretasi oleh penikmatnya masing-masing. Menurut Bahari (2008: 64) dari media ekspresi tesebut seni juga dapat berfungsi sebagai media komunikasi antara pencipta dan penikmat seni.

Seni pada dasarnya adalah wujud atau bentuk berupa artefak, gambar, tulisan, gerak, bunyi, dan lain-lain yang bisa diindera oleh panca indera manusia (Sumarjo, 2000: 135). Seni musik merepresentasikan bunyi melalui nada-nada atau bunyi-bunyian yang sudah dikonsep sedemikan rupa sehingga mengahsilkan komposisi yang indah. Seni tari dengan gerakan yang sudah ditata oleh koregrafernya sehingga gerakan yang ditariakan terlihat indah dan harmonis. Begitupun dengan seni yang lainnya, mempunyai ciri khas dan keunikan tersendiri yang menjadi suatu wujud sebagai identitas seninya itu sendiri.

Seni secara umum dibagi dalam beberapa jenis, seni gerak (tari), seni tulisan (sastra), seni pertunjukan (teater), seni suara (musik) dan lain-lain. Seni musik adalah seni yang menghasilkan bunyi secara teratur. Seperti alunan melodi, harmoni, ritmik, yang dihasilkan dari satu atau beberapa alat musik atau vocal oleh seorang pemain atas petunjuk komposer melalui suatu tulisan (notasi balok). Sehingga bunyi yang dihasilkan oleh seorang pemain melalui alat musiknya atau vocalnya terdengar merdu dan indah. Konsep seni musik terbentuk karena ada seorang yang membuat suatu karya musiknya itu sendiri (komposer) kemudian ada seorang atau beberapa pemain yang mengkomunikasikan atau membunyikan suatu karya yang diciptakan oleh seorang komposer kemudian ada alat musiknya sebagai media yang menjebatani antara komposer dengan pemain sehingga menghasilkan nada yang unik dan harmonis. 
Setiap alat musik mempunyai keunikan dan ciri khasnya masing-masing. Ada yang sebagai alat musik melodi (tidak membentuk suatu akord) ada juga sebagai alat musik melodi dan pengiring (membentuk suatu akord). Alat musik melodi biasanya dimainkan oleh jenis alat musik tiup kayu dan logam seperti flute, oboe, trumpet, horn, tuba dan lain-lain. Sedangkan alat musik pengiring biasanya dimainkan oleh piano, keyboard, gitar dan lain-lain.

Alat musik yang terakhir disebutkan dalam paragraf sebelumnya memiliki karakteristik tertentu. Alat musik gitar khususnya gitar klasik adalah sebuah media yang dimainkan oleh mahasiswa dan mahasiswi Prodi Pendidikikan Seni Pertunjukan (PSP) Fakultas Keguruan dan Ilmu Pendidikan (FKIP) Universitas Sultan Ageng Tirtayasa (Untirta) untuk memainkan sebuah repertoar yang sudah ada diciptkan oleh komposer. Para mahasiswa/i memainkan alat musik ini dengan cara membaca simbol-simbol (notasi balok) tertentu yang ada dalam sebuah repertoar. Sehingga cara tersebut menghasilkan alunan melodi yang indah dan harmonis ketika dimainkan oleh mahasiswa/i PSP FKIP Untirta.

Sebuah proses dalam memainkan reportoar yang indah dan merdu, tentunya ada sebuah usaha dan upaya yang dihasilakan. Upaya tersebut membentuk sebuah nilai-nilai yang tertanam dalam diri seorang mahasiswa/i PSP FKIP Untirta atau pemain gitar klasik. Pembelajaran gitar klasik syarat akan nilai-nilai yang ada di dalamnya. Proses pembelajaran tersebut membentuk individu menjadi pribadi yang memiliki nilai-nilai tertentu. Dari proses interaksi antara pemain dan repertoar yang akan dimainkan oleh alat musik gitar klasik memiliki nilai-nilai tertentu yang terkandung di dalamnya.

Nilai adalah sesuatu yang bersifat subjektif, tergantung pada manusia yang menilainya apakah sesuatu itu memiliki nilai atau tidak. Nilai pada dasarnya sesuatu yang berharga, bermutu dan memiliki kebermanfaatan bagi manusia. Pembelajaran gitar klasik di Prodi PSP FKIP Untirta memiliki nilai-nilai tersendiri dalam representasi permainan yang dimainkan oleh seorang mahasiswa/i. Ketika seorang pemain gitar klasik atau mahasiswa/i memainkan sebuah repertoaar dari komposer tertentu maka teks atau partitur yang dimainkannya merepresentasikan nilai-nilai yang terkandung di dalam sebuah permainan gitarnya. Hal ini akan menjadi bermutu ketika subjek atau seseorang melihat suatu fenomena tersebut sebagai sesuatu yang memiliki nilai.

Pendidikan merupakan suatu usaha manusia dalam membiasakan sesuatu yang baik untuk dirinya dan orang lain. Pembiasaan ini selalu tertanam pada dirinya hingga menularkan suatu kebaikan bagi orang di sekitarnya. Pembelajaran gitar klasik secara tidak langsung adalah pembiasaan seseorang dalam melakukan upaya kebaikan untuk dirinya dan orang lain. Proses penamaman tersebut adanya interaksi dari diri si pemain gitar klasik dengan teks yang sedang dipelajarinya. Bagaimana seorang pemain gitar klasik memainkan teks atau partitur sesuai dengan kaidah-kaidah yang berlaku. Sehingga interaksi 
tersebut menghasilkan pembelajaran yang optimal yang bisa dirakasan manfaatnya oleh dirinya dan orang lain.

Konsep nilai dan pendidikan yang akan dibahas disini adalah bagaimana interaksi mahasiswa/i gitar klasik dalam mempelajari repertoar yang sudah ada. Sehingga interaksi tersebut nantinya akan menghasilkan nilai-nilai pendidikan di dalmnya. Nilai pendidikan Menurut Amalia, Novita Rihi (2010: 32) merupakan sesuatu yang memiliki nilai kebaikan. Kebaikan tersebut bermanfaat bagi kehidupan yang diperoleh melalui suatu proses pengubahan sikap dan perilaku dalam upaya mendewasakan dirinya melalui proses pembelajaran. Menurut Ahmadi dan Nur dalam Elneri dkk. (2018: 7) nilai-nilai pendidikan dibagi ke dalam beberapa aspek salah satunya adalah nilai tentang keindahan dan estetis. Estetis berhunbungan dengan olah rasa dalam mencapai suatu keindahan. Kemudian komponen-komponen nilai-nilai pendidikan dikelompokan menjadi delapan belas, salah satunya yaitu disiplin, kerja keras, dan gemar membaca.

\section{Metode}

Penelitian ini menggunakan metode kualitatif yang diuraikan secara deskriptif untuk memperoleh data tentang nlai-nilai pendidikan dalam pembelajaran gitar klasik di Prodi PSP FKIP Untirta. Mengapa metode kualitatif dipilih, dikarenakan permasalahan yang akan dikaji belum begitu jelas, holistik, kompleks, dan dinamis (Wahyu dkk, 2015: 855). Penelitian ini menggunakan pendekatan fenomenologi. Fenomonolgi ialah aliran pemikiran yang berawal atau berakar dari ilmu filsafat. Aliran pemikiran ini mengaggap bahwa fenomena atau gejala adalah sumber pengetahuan dan kebenaran. Fenomenologi adalah ilmu pengetahuan yang mempelajari tentang sesuatu yang tampak atau menampakan diri (Djamal, 2015: 106). Proses pembelajaran gitar klasik di Prodi PSP FKIP Untirta adalah suatu fenomena yang tampak atau menampakan dirinya dihadapan orang banyak untuk diinterpretasikan dalam fenomena tersebut. Sehingga apa yang tampak dari fenomena tersebut bisa tafsirkan oleh siapapun berdasarkan kesadaran si penafsirnya.

Pendekatan fenomenologi didasarkan pada pandangan bahwa pengalaman manusia diperoleh melalui interpretasi atau suatu objek. Menurut pandangan fenomenologi, suatu objek mungkin orang atau barang, situasi dan peristiwa tidak memiliki arti dengan sendirinya kecuali ditafsirkan melalui interpretasi oleh manusia. Pembelajaran gitar klasik yang ada di Prodi PSP FKIP Untirta suatu fenoena yang menampakan dirinya untuk diinterpretasi oleh penulis sehingga fenomena tersebut nantinya memiliki arti tertentu untuk diungkap.

Lokasi penelitian ini di Prodi PSP FKIP Untirta Provinsi Banten. Subjek penelitian ini adalah mahasiswa/i yang berperan aktif dalam proses pembelajran gitar klasik di Prodi PSP FKIP Untirta. Penelitian ini dilakukan pada saat mahasiswa/i berlatih secara langsung secara individu di lingkungan PSP FKIP 
Untirta. Waktu penelitian dilakukan selama kurang lebih tiga bulan yaitu dari bulan maret 2020 sampai mei 2020. Teknik pegnumpulan data menggunakan observasi partisipatif, wawancara mendalam, dan dokumentasi. Analisis data dalam penelitian ini ada tiga tahap, (1) reduksi data. Data yang ada di lapangan direduksi dan diklasifikasikan berdasarkan kriterianya. Menurut Rizali (2018: 91) ada tiga tahap dalam mereduksi data; (a) meringkas data, (b) mengkode, (c) menelusur tema, (d) membuat gugus-gugus. (2) penyajian data. Data yang telah direduksi kemudian disajikan dalam bentuk kata atau gambar. (3) penarikan kesimpulan.

\section{Hasil dan pembahasan}

\section{Pembelajaran gitar klasik di PSP FKIP Untirta}

Gitar klasik adalah sarana pendukung dalam sebuah media pembelajaran. Menurut Miswar (2017: 34) pembelajaran yaitu suatu aktifitas yang dilakukan oleh individu atau kelompok secara sadar dan sengaja. Tujuan dari pembelajaran untuk memperoleh suatu pengalaman yang bernilai dan tentunya merubah suatu perilaku individu yang tadinya tidak tahu menjadi tahu, yang tadinya tidak bisa menjadi bisa. Pembelajaran gitar klasik yang dilakukan oleh mahasiswa/i PSP FKIP Untirta adalah suatu proses pendewasaan dalam memainkan alat musik tersebut. Proses tersebut ditemukan dari berbagai macam kasus yang berbeda dari setiap repertoar gitar. Tentunya setiap repertoar mempunyai kesulitan dan ciri khas tersendiri. Mulai dari kesulitan teknik, score yang rumit, repertoar berdurasi panjang, mengekspresikan repertoar sesuai petunjuk score dan lain sebagainya. Dengan demikian proses tersebut membentuk pola permainan mereka menjadi lebih baik dan berkembang dari sebelumnya. Sehingga secara tidak langsung proses pembelajaran tersebut membentuk pendewasaan dalam permainan gitar mereka.

Pembelajaran gitar klasik di PSP FKIP Untirta dilakukan secara individu dan kelompok. Mereka berlatih secara mandiri dalam memainkan repertoar yang sudah ada. Seperti memainkan repertoar gitar untuk solo. Mereka memainkan repertoar tersebut agar mampu menguasai teknik tertentu yang ada dalamnya. Salah satunya Etude No. 1 dari Heitor Villa Lobos yang sedang dipelajari oleh Kinan Mahasiswa angkatan 2019. Teknik tersebut membenuk pola arpeggio yang dilakukan oleh ke empat jari kanan secara diulang-ulang. Sehingga dengan menguasai teknik yang ada dalam reperoar tersebut, akan membentuk pola permainan gitarnya ke arah yang lebih baik. Selain mempelajari gitar solo, mereka mempelajari repertoar gitar klasik yang dimainkan lebih dari satu orang. Salah satunya repertoar Lightly Row yang dimainkan secara duet. Aynan dan Dea mahasiswa angkatan 2018 memainkan repertoar duet bertujuan untuk mengembangkan permainan gitarnya, karena menurut mereka jika hanya bermain secara individu saja tidak akan tau bagaimana caranya menjadi 
pengiring yang baik dan benar. Tentunya juga menahan ego satu sama lain ketika bermain secara duet.

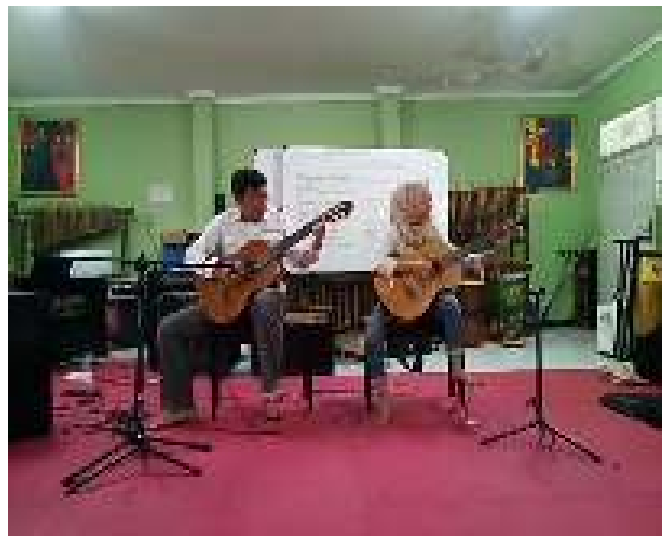

Gambar 1. Pembelajaran Gitar Klasik di PSP FKIP Untirta

Selain itu, para mahasiswa/i PSP FKIP Untirta dalam memainkan repertoar gitar klasik dengan cara bertahap dan bertingkat. Mulai dari repertoar yang dasar dilanjut dengan repertoar yang cukup kompleks. Salah satu repertoar dasar yang sedang dimaiknan oleh Dea adalah Spring's Message. Repertoar tersebut sangat dasar bagi gitaris klasik pemula. Dari hasil analisa penuis kenapa repertoar tersebut dikatagorikan dasar, karena tidak membutuhkan teknik yang cukup sulit. Yaitu hanya membutuhkan ketepatan nada yang dimainkan di dawai 1 dan 2 pada fret gitar 1 dan 3. Kemudian repertoar yang cukup kompleks dimainkan oleh Kinan adalah Asturias. Repertoar ini sangat membutuhkan teknik yang tinggi, selain itu dimainkan dengan tempo Alegro Ma Non Troppo (cepat) menggunakan not seperenambelas. Tujuan mempelajari gitar klasik secara bertahap agar permainan gitar mereka tersrtuktur. Menurut Kinan angkatan 2019 salah satu mahasiswa PSP FKIP Untirta mengatakan bahwa memainkan repertoar gitar secara bertahap itu cukup penting. Supaya kita paham tingkat kesulitan dalam repertoar gitar itu berbeda-beda. Jika kita baru belajar gitar klasik tentunya harus mempelajari repertoar yang fundamental dulu, jangan langsung memainkan repertoar yang tingkatnya lebih tinggi. Ini akan menjadi kendala ketika baru mempelajari gitar klasik.

Selain itu proes pembelajaran gitar di PSP FKIP Untirta mempelajari berbagai macam repertoar yang sudah diciptakan oleh komposer sebelumnya, mulai dari repertoar di zaman Barok, Romatik, Klasik, sampai zaman Modern. Repertoar tersebut dipelajari dan dimainkan secara bergantian. Jika mereka sudah bisa memainkan repertoar di zaman tertentu, mereka akan mempelajari repertoar zaman berikutnya atau yang belum pernah mereka mainkan di zaman tertentu. Hal ini dilakukan oleh para mahasiswa/i agar pegetahuan mereka dalam referensi repertoar gitar banyak dan beragam. Sehingga dari banyaknya referensi repertoar tersebut membentuk pola permainan yang diharapkan. 


\section{Nilai-nilai pendidikan dalam proses pembelajaran gitar klasik di PSP FKIP Untirta}

\section{Nilai disiplin}

Pembelajaran gitar klasik tentunya membutuhkan disiplin yang tinggi. Dengan disiplin yang tinggi tentunya akan membentuk perilaku yang baik. Hal ini disampaikan oleh Annisa (2019: 3) menurutnya menanamkan disiplin yang tepat pada sesorang atau individu akan memebentuk perilaku yang baik. Para mahasiswa/i PSP FKIP Untirta ditutut berlatih secara teratur agar proses pembelajaran gitar membuahkan hasil yang optimal. Dengan latihan secara teratur, para mahasiswa/i mempelajari teknik, scale, etude, dan repertoar gitar secara rutin yang dilakukan secara terus menurus selama berjam-jam. Seperti halnya yang dilakukan mahasiswi PSP FKIP Untirta, Ifa angkatan 2017. Mahasiswi tersebut berlatih secara disiplin jika tidak ada perkuliahan pada hari itu. Menurutnya di sela waktu kosong sebisa mungkin dia menyempatkan latihan secara teratur selama berjam-jam di lingkungan PSP FKIP Untirta secara mandiri atau bersama temannya. Hal ini telah dilakukan oleh Ifa secara teratur semenjak dirinya mulai mempelajari gitar klasik. Sehingga proses penanaman nilai disiplin dalam pembelajaran gitar klasik terinternalisasi pada dirinya.

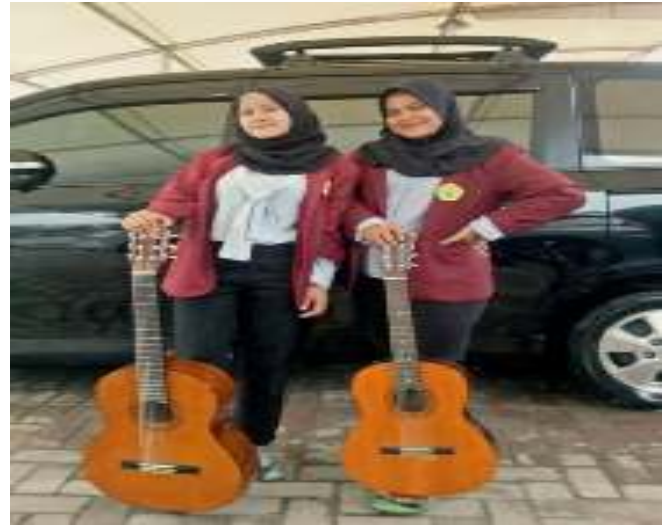

Gambar 2. Penanaman Nilai Disiplin oleh Mahasiswi

Penanaman nilai disiplin dalam mempelajari gitar klasik tentunya sangat diperlukan. Tujuannya agar membentuk pola permainan yang diinginkan. Seperti displin dalam berlatih teknik arpeggio, slur, scale secara teratur selama berjam-jam. Dengan disiplin berlatih teknik tersebut akan menunjang kedalam repertoar tertentu yang nantinya ketika memainkan repertoar tersebut akan sangat mudah bagi seorang gitaris klasik memainkannya. Selain disiplin melatih teknik juga disiplin melatih etdue secara teratur. Latihan etude secara disiplin akan menghasilkan permainan yang optimal. Di dalam etude terdapat teknik tertentu yang lebih spesifik, seperti Etude No. 1 dari Heitor Villa Lobos. Etude tersebut membahas pola teknik arpegio yang terus dimainkan oleh jari tangan kanan secara diulang-ulang dari awal sampai akhir karya. Dengan berlatih etude seorang gitaris klasik akan menguasai teknik tertentu yang nantinya sangat 
berguna baginya. Nilai disiplin dalam proses pembelajaran gitar klasik harus dilakukan secara terus menerus dengan durasi waktu yang cukup lama dan teratur. Dengan latihan secara disiplin seorang gitaris klasik akan menguasai pola permainan secara optimal dan maksimal sesuai yang diharapkan.

\section{Nilai terbiasa membaca}

Memainkan gitar klasik identik dengan membaca notasi balok atau biasa disebut dalam istilah musik score. Mahasiswa/i PSP FKIP dalam memainkan repertoar yang sudah ada selalu membaca score. Mereka memainkan repertoar berdasarkan score seperti tanda dinamik, posisi jari dimainkan di fret berapa, menggunakan tempo cepat atau lambat dan lain-lain. Seperti repertoar Romance De Amor yang berasal dari Spanyol. Repertoar tersebut dimainkan oleh Aynan angkatan 2018 mahasiswa PSP FKIP Untirta. Dari awal sampai akhir, Aynan memainkan repertoar tersebut apa yang tertulis dalam score, yaitu memainkan repertoar itu apa adanya berdasarkan pertintah yang ditulis oleh sang komposer. Seperti tanda biramanya menggunakan tiga perempat, temponya menggunakan allegro moderato, tanda mulanya menggunakan 1 kres kemudian dibagian tengah dari lagu tersebut modulasi ke 4 kres.

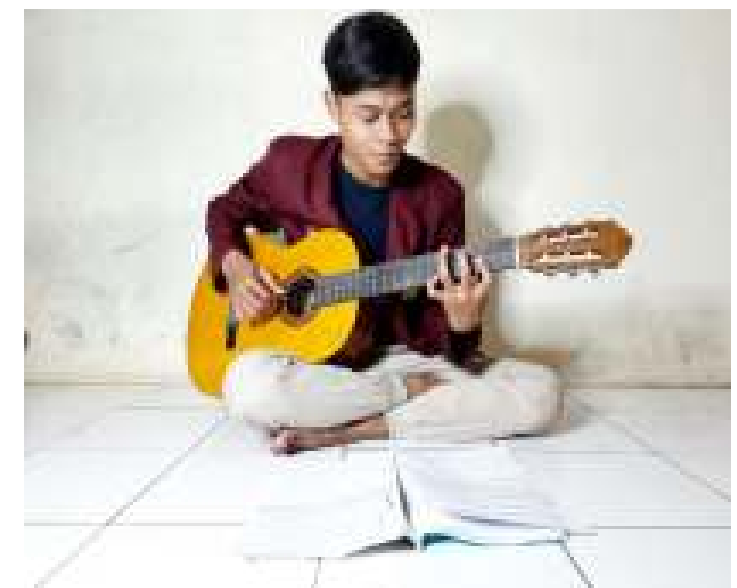

Gambar 3. Penanaman Nilai Terbiasa Membaca oleh Mahasiswa

Membaca score gitar sangat diwajibkan dalam mempelajari atau memainkan gitar klasik. Jika para mahasiswa tidak bisa membaca score, akan menjadi permasalahan tersendiri dalam memainkan sebuah repertoar gitar. Mungkin bisa saja memainkan repertoar tersebut tanpa membanca score yaitu dengan metode solfegio (mendengar repertoar tersebut melalui audio), tetapi hasilnya kurang optimal dibandingkan dengan membaca score repertoar secara langsung. Dengan demikian nilai-nilai pendidikan secara tidak langsung terinternalisasi oleh mahasiswa ketika memainkan repertoar Lagrima dari F. Tarrega. 


\section{Nilai kerja keras}

Menurut Elfrindi, dkk dalam Sulastri dan Alimin (2017: 158) kerja keras adalah sifat indvidu yang tidak mudah berputus asa yang disertai kemauan keras dalam berusaha dalam mencapai tujuan dan cita-citanya. Kosep kerja keras dalam pembelajaran gitar klasik yang dilakukan oleh mahasiswa/i PSP FKIP Untirta adalah suatu upaya memainkan lagu yang akan dimainkan dari awal sampai akhir repertoar. Mereka berlatih dengan gigih untuk bisa memainkan repertoar tersebut dengan maksimal. Hal ini ditunjukan oleh Aynan angkatan 2018 mahasiswa PSP FKIP Untirta ketika menggarap satu repertoar gitar yang berjudul Asturias dari seorang komposer Isaac Albeniz. Dia berlatih selama berjam-jam untuk menggarap repertoar tersebut. Menurutnya jika ingin berhasil memainkan repertoar tersebut maka kita harus berlatih secara gigih dan tanpa menyerah dengan meluangkan waktu yang cukup lama. Mengingat repertoar tersebut cukup sulit dimainkan jika tidak mempunyai dasar permainan gitar klasik.

Nilai-nilai kerja keras tertuang dalam proses memainkan repertoar dari Isaac Albeniz. Repertoar tersebut dimainkan oleh Kinan tanpa mengenal rasa putus asa dan pantang menyerah walaupun baginya repertoar tersebut sangat sulit. Dia tetap berusaha seoptimal mungkin untuk bisa memainkan repertoar tesebut secara baik dan benar. Dengan demikian nilai kerja keras dalam proses memainkan repertoar Astturias secara tidak langsung terinternaisasi pada diri Aynan.

\section{Nilai olah rasa}

Olah rasa menurut Yaumi (2016: 52) ada empat langkah mulai dari tahapan yang sederhana sampai tahapan yang kompleks. Yang pertama; penerimaan. Seorang pemain gitar klasik atau mahasiswa/i PSP FKIP Untirta akan menerima sebuah repertoar gitar yang telah dibuat oleh seorang komposer. Sehingga repertoar yang diciptakan oleh seorang komposer akan dimainkan sesuai dengan simbolsimbol yang tertulis dalam sebuah score gitar. Mulai dari teknik permainan gitar, dinamik lagu, tempo, tanda mula dan bentuk musiknya. Para mahasiswa/i PSP FKIP Untirta yang memainkan gitar klasik baik itu karya yang sederhana ataupun kompleks memainkan karya tersebut sesuai dengan simbol yang sudah ada. Hal tersebut diterima dengan apa adanya. Dengan demikian, repertoar yang dimainkan oleh mahasiswa tidak diinterpretasi ulang dalam memainkan karya yang sudah ada.

Kedua; tanggapan. Mahasiswa/i PSP FKIP Untirta atau pemain gitar klasik akan menanggapi sebuah repertoar gitar yang telah dibuat oleh seorang komposer. Dari olah rasa ini, seorang pemain (Mahasiswa/i PSP FKIP) akan merasakan perbedaan karya komposer yang satu dengan komposer yang lain. Sehingga pemain gitar klasik yang sedang memainkan karya komposer tersebut akan menanggapi karya yang sedang dimainkan. Kenapa repertoar tersebut pada 
bagian tertentu hanya menggunakan teknik apoyando, kenapa tidak semuanya saja menggunakan teknik tirando dalam repertoar tertentu. Kemudian mengapa ada sebuah perbedaan antara repertoar zaman Barok dan Modern. Hal ini akan direspon oleh alam bawah sadar mereka, mengapa setiap repertoar memiliki karakteriktik tertentuk sehingga memiliki ciri khas atau perbedana satu sama lain.

Ketiga; penilaian. Pemain gitar klasik (PSP FKIP Untirta) akan menilai suatu repertoar yang sedang dimainkannya berdasarkan pengalaman olah rasanya. Tentunya sebagai pemain gitaris klasik, seorang pemain mempunyai berbagai referensi repertoar mulai dari zaman Barok sampai Modern. Ketika mahasiswa/i PSP FKIP Untirta memainkan karya J.S. Bach dalam alat musik gitar klasik akan menilai karya tersebut seperti melodi yang mengalir tanpa henti. Melodi bawah dan melodi bass berdiri sendiri atau dengan istilah kontrapung. Beda halnya ketika memanikan karya dari F. Tarega, karya tersebut terkesan lebih ekspresif dan emosional dibandingkan dengan J.S. Bach.

Keempat; internalisasi. Tahapan terakhir ini, tahapan dimana mahasiswa/i PSP FKIP Untirta yang memainkan gitar klasik akan menginternalisaikan repertoar yang sedang atau telah dimainkannya melalui olah rasanya. Ini akan terinternalisasi cukup lama asalkan mahasiswa/i tersebut selalu berlatih memainkan karya yang sudah dikuasainya.

\section{Kesimpulan}

Proses pembelajaran gitar klasik yang dilakukan oleh mahasiswa dan mahasiswi Prodi Pendidikan Seni Pertunjukan Fakultas Keguruan dan Ilmu Pendidikan Universitas Sultan Ageng Tirtayasa adalah suatu upaya untuk mempelajari dan memainkan repertoar, etude, dan teknik baik secara individu maupun kelompok. Upaya tersebut terus dipelajari dari berbagai tahap dan tingkatan, mulai dari tahap yang paling dasar sampai dengan tahap yang cukup kompleks. Sehingga pembelajaran tersebut menghasilkan sesuatu yang diharapkan. Yaitu menghasilkan alunan melodi yang indah dan harmonis ketika memainkan repertoar atau etude tertentu dari awal sampai akhir repertoar atau etude.

Nilai-nilai pendidikan yang terkandung dan diaktualisasikan oleh mahasiswa dan mahasiswi Prodi Pendidikan Seni Pertunjukan Fakultas Keguruan dan Ilmu Pendidikan Universitas Sultan Ageng Tirtayasa pada proses pembelajaran gitar klasik yaitu nilai pendidikan disiplin, kerja keras, terbiasa membaca, dan olah rasa. Nilai-nilai pendidikan terinternalisasi melalui pembelajaran gitar klasik oleh mahasiswa dan mahasiswi yang sedang mempelajari gitar klasik melalui repertoar gitar yang sudah ada. 


\section{Daftar pustaka}

Amalia, Novita Rihi (2010). Analisis Gaya Bahasa dan Nilai-Nilai Pendidikan Novel Sang Pemimpi Karya Andrea Hirata. Tesis Magister. Universitas Sebelas Maret

Annisa, Fadillah. (2019). Penanaman Nilai-Nilai Pendidikan Karakter Disiplin Pada Siswa Sekolah Dasar. Perspektif Pendidikan dan Keguruan, 10 (1), 1-7.

Bahari, Nooryan. (2008). Kritik Seni Wacana Apresiasi dan Kreasi. Yogyakarta: Pustaka Pelajar.

Djamal, M. (2015). Paradigma Penelitian Kualitatif. Yogyakarta: Pustaka Pelajar.

Elnera, dkk. (2018). Nilai-Nilai Pendidikan Dalam Novel Mamak Karya Nelson Alwi. Jurnal Puitika, 14 (1), 1-13.

Miswar. (2017). Teori Pembelajaran CBSAK Sebagai Sebuah Teori Alternatif. Jurnal Basicedu, 1 (2), 32-41.

Rijali, Ahmad. (2018). Analisis Data Kualitatif. Jurnal Alhadharah, 17 (33), 8195.

Sumarjo, jakob. (2000). Filsafat Seni. Bandung: Penerbit ITB.

Yaumi, Muhmmad. (2016). Pendidikan Karakter (Landasasan, Pilar dan Implementasi). Jakarta: Prenadamedia Group.

Sulastri, Saptiana dan Alimin, Al Ashadi. (2017). Nilai Pendidikan Karakter Kerja Keras Dalam Novel 2 Karya Donny Dhirgantoro. Jurnal Pendidikan Bahasa, 6 (2), 156-168.

Wahyu dkk. (2015). Menanamkan Nilai Disiplin Anak Pada Lingkungan Keluarga Di Desa Sungai Pinang Lama Kecamatan Sungai Tabuk Kabupaten Banjar. Jurnal Pendidikan Kewarganegaraan, 5 (10), 853-858 